\title{
Armazenamento de sementes de soja tratadas com fungicida, inseticida e micronutriente e recobertas com polímeros líquido e em pó
}

\author{
Storage of soybean seed treated with fungicide, insecticide and micronutrient and coated with liquid \\ and powered polymer
}

\author{
Suemar Alexandre Gonçalves Avelar ${ }^{\mathrm{F}^{*}}$ Leopoldo Baudet $^{\mathrm{II}}$ Silmar Teichert Peske ${ }^{\mathrm{II}}$ \\ Marcos Paulo LudwigII Geliandro Anhaia Rigo ${ }^{\mathrm{IV}}$ Renato Lopes Crizel ${ }^{\mathrm{IV}}$ Sandro de Oliveira ${ }^{\mathrm{IV}}$
}

\section{RESUMO}

\begin{abstract}
O objetivo deste trabalho foi avaliar o desempenho de sementes de soja tratadas com fungicida, inseticida, micronutrientes e recobertas com polímero líquido e em pó, durante seis meses de armazenamento. Sementes de soja da cultivar 'CD 209' foram submetidas aos seguintes tratamentos: testemunha, fungicida Fludioxonil + Metalaxyl - M (Maxim $X L^{\circledR}-100 \mathrm{~mL} 100 \mathrm{~kg}^{-1}$ de sementes), inseticida Thiametoxan (Cruiser 350FS ${ }^{\circledast}$ - 200mL100kg-1 de sementes), micronutriente ComoFix ${ }^{\circledast}\left(165 \mathrm{mL100 \textrm {kg } ^ { - 1 }}\right.$ de sementes - 24,75mL Mo e $2,475 \mathrm{~mL}$ Co) e a mistura fungicida + inseticida + micronutriente. Os mesmos tratamentos foram repetidos utilizando o polímero líquido Sepiret 9241 B Green (400mL $100 \mathrm{~kg}^{-1}$ de semente) e também o polímero em pó Sepiret Flo

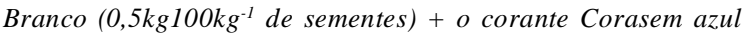
$\left(50 \mathrm{~mL} 100 \mathrm{~kg}^{-1}\right.$ de sementes). A qualidade das sementes foi avaliada durante 180 dias de armazenamento pelos testes de germinação e vigor (primeira contagem de germinação, envelhecimento acelerado, comprimento de plântulas, hipocótilo e raiz). O recobrimento de sementes de soja com polímeros e produtos protetores as protege durante o armazenamento, enquanto o polímero em pó reduz a germinação das sementes e há interação entre polímeros $e$ produtos sobre o desempenho de sementes após 180 dias de armazenamento.
\end{abstract}

Palavras-chave: Glycine max, germinação, qualidade fisiológica, film coating.

\section{ABSTRACT}

The objective of this research was to evaluate the quality of soybean seeds treated and coated with fungicide, insecticide, micronutrients and polymers, during six months of storage. Soybean seeds cultivar 'CD 209' were submitted to the following treatments: control, fungicide Fludioxonil + Metalaxyl - M (Maxim XL - $100 \mathrm{~mL} 100 \mathrm{~kg}^{-1}$ seeds), insecticide Thiametoxan (Cruiser $350 \mathrm{FS}^{\circledast}-200 \mathrm{~mL} 100 \mathrm{~kg}^{-1}$ seeds), micronutrient ComoFix ${ }^{\circledast}\left(165 \mathrm{~mL} 100 \mathrm{~kg}^{-1}\right.$ seeds - 24,75mL Mo and $2,475 \mathrm{~mL} \mathrm{Co}$ ) and the mixture fungicide + insecticide + micronutrient. The same treatments were repeated using the liquid polymer Sepiret 9241 B Green (400mL100 kg-1 seed) and also powder polymer Sepiret Flo Branco $\left(0,5 \mathrm{~kg}^{100 \mathrm{~kg}^{-1}}\right.$ seeds $)+$ colorant Corasem blue (50mL100kg ${ }^{-1}$ seeds). Seed quality was evaluated during 180 days on storage by the germination test and vigor tests (first count germination, accelerated aging, seedling, hypocotyl and root length). Soybean seed coating with polymers and protecting products protect the seeds during the storage while powder polymer reduces soybean's seeds germination and there is interaction between polymer's and products over seed performance after storage.

Key words: Glycine max, germination, physiologic quality, film coating.

\section{INTRODUÇÃO}

O tratamento de sementes de soja é uma prática técnica e economicamente recomendada, desde que utilizados produtos ou misturas de produtos adequados, na dosagem recomendada e distribuídos uniformemente em todo o lote de sementes. À medida que aumenta a percepção do valor da semente e a

'Programa de Pós-graduação em Ciência e Tecnologia de Sementes, Faculdade de Agronomia Eliseu Maciel (FAEM), Universidade Federal de Pelotas (UFPel), 96001-900, Pelotas, RS, Brasil. E-mail:suemaralexandre@yahoo.com.br. *Autor para correspondência. "Departamento de Fitotecnia, FAEM, UFPel, Pelotas, RS,Brasil.

"IIInstituto Federal de Educação, Ciência e Tecnologia do Rio Grande do Sul, Campus Ibirubá, Ibirubá, RS, Brasil.

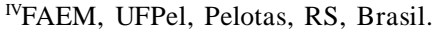


importância de proteger e/ou melhorar o seu desempenho, aumenta a gama de produtos disponíveis para o tratamento de sementes, com diferentes finalidades, como proteção (fungicidas ou inseticidas) ou nutrição (micronutrientes), tendo como objetivo principal melhorar o desempenho da semente, tanto no aspecto fisiológico como econômico.

O tratamento de sementes com fungicida, além de reduzir danos causados por fungos nelas presentes, também visa ao controle de microrganismos que atacam as plântulas na fase de estabelecimento no campo (HENNING, 2005). O tratamento de sementes com inseticida tem sido recomendado para soja contra pragas de difícil controle, como o tamanduá ou bicudo da soja (Sternechus subsignatus), os corós (Phyllophagacuyabana e Phyllafaga capillata.), o percevejo castanho (Scaptocoris castanea e Atarsacoris brachiariae) e a lagarta elasmo Elasmopalmus lignosellus (GRUTZMACHER, 2007). A quantidade requerida de micronutrientes e sua distribuição ótima se tornam crítica em solos em que ocorrem condições adversas para a solubilização dos nutrientes, bem como para o crescimento vigoroso das raízes (KIRKBY \& RÖMHELD, 2007), tornando, assim, o fornecimento via sementes uma forma eficaz de adubação.

Para assegurar a qualidade do tratamento de sementes, é adicionado um polímero adesivo, formando um filme de recobrimento com os produtos, contribuindo para que a quantidade adequada dos ingredientes ativos aplicados seja aderida à superfície das sementes garantindo o seu desempenho (KUNKUR et al., 2007) e proporcionando sementes com boa aparência, coloração e aderência (BAYS et al., 2007).

Com o tratamento de sementes passando a fazer parte do fluxograma de algumas unidades de beneficiamento, é importante conhecer seus efeitos no potencial de armazenamento. $\mathrm{O}$ tratamento de sementes com fungicidas e polímeros não prejudicou a germinação de sementes de feijoeiro durante quatro meses de armazenamento (PIRES et al., 2004). Sementes de milho com alta qualidade fisiológica inicial, tratadas com inseticida, fungicida e polímeros, foram armazenadas por seis meses sem prejuízos a sua qualidade (PEREIRA et al., 2005). Em sementes de algodão, o tratamento com fungicida, inseticida e polímero propiciou sementes com maior porcentagem de germinação após nove meses de armazenamento (KUNKUR et al., 2007). Os polímeros não afetaram a qualidade fisiológica de sementes de soja quando comparado a sementes sem tratamento, embora para sementes tratadas com thiram + thiabendazole o potencial de armazenamento tenha sido maior que daquelas sem fungicida (PEREIRA et al., 2007).

O objetivo deste trabalho foi avaliar o desempenho de sementes de soja tratadas com fungicida, inseticida, micronutrientes e recobertas com polímero líquido e em pó, durante seis meses de armazenamento.

\section{MATERIAL E MÉTODOS}

Sementes de soja da cultivar 'CD 209', oriundas da empresa Coodetec, Cascavel-PR, foram submetidas aos seguintes tratamentos: testemunha, fungicida Fludioxonil + Metalaxyl - M (Maxim XL ${ }^{\circledR}$ $100 \mathrm{~mL}^{100 \mathrm{~kg}^{-1}}$ de sementes), inseticida Thiametoxan (Cruiser 350FS ${ }^{\oplus}$ - 200mL $100 \mathrm{~kg}^{-1}$ de sementes), micronutriente ComoFix ${ }^{\circledast}\left(165 \mathrm{~mL} 100 \mathrm{~kg}^{-1}\right.$ de sementes $-24,75 \mathrm{~mL}$ Mo e $2,475 \mathrm{~mL} \mathrm{Co}$ ) e a mistura fungicida + inseticida + micronutriente. Os mesmos tratamentos foram repetidos utilizando a testemunha (sem o polímero), o polímero líquido Sepiret 9241 B Green

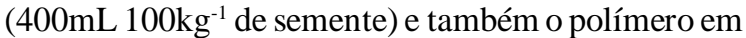
pó Sepiret Flo Branco (0,5 kg 100 $\mathrm{kg}^{-1}$ de sementes) +o corante Corasem azul (50mL 100 $\mathrm{kg}^{-1}$ de sementes). Para que a calda total (produto + água) atingisse o volume máximo de $600 \mathrm{~mL}^{100 \mathrm{~kg}^{-1}}$ de sementes, foi adicionada água. $\mathrm{O}$ recobrimento das sementes foi feito manualmente, utilizando $500 \mathrm{~g}$ de sementes por parcela, com a mistura dos produtos em sacos plásticos e, após a adição das sementes, agitação até a completa distribuição dos produtos e cobertura das sementes.

Após o tratamento, parte das sementes foram submetidas à avaliação da qualidade fisiológica inicial e outra parte foi acondicionada em caixas de papelão e armazenada em sala com temperatura constante de $20^{\circ} \mathrm{C}$, sem controle da umidade relativa do ar para avaliação da qualidade fisiológica aos 60, 120 e 180 dias após o armazenamento. Para avaliação da qualidade das sementes, seguiu-se à determinação do teor de água e aos testes de germinação e vigor (primeira contagem de germinação, envelhecimento acelerado e comprimento de plântulas).

A determinação do teor de água foi efetuada em duas subamostras de 100 sementes, pelo método de estufa a $105 \pm 3^{\circ} \mathrm{C}$, durante 24 horas, sendo expresso em percentagem em base úmida (BRASIL, 2009).

$\mathrm{O}$ teste de germinação foi conduzido com quatro subamostras de 50 sementes por repetição, em substrato rolo de papel germitest umedecido com água destilada na quantidade equivalente a três vezes a massa do papel seco e mantidos à temperatura de $25^{\circ} \mathrm{C}$. As contagens foram realizadas aos cinco e oito dias após semeadura e os resultados foram expressos em porcentagem (BRASIL, 2009). As plântulas consideradas normais na primeira contagem (aos cinco dias) tiveram os resultados expressos em porcentagem como primeira contagem de germinação.

Para o envelhecimento acelerado, 220 sementes por repetição foram distribuídas sobre telas de alumínio, suspensas no interior de caixas plásticas 
tipo gerbox adaptadas, funcionando como compartimentos individuais, onde foram adicionados $40 \mathrm{~mL}$ de água destilada. As caixas foram tampadas e mantidas em condições controladas de temperatura e umidade relativa do $\operatorname{ar}\left(41^{\circ} \mathrm{C}\right.$ e $100 \%$ de UR do ar) por 48 horas (MARCOS FILHO, 2005). Após esse período, as sementes foram submetidas ao teste de germinação (BRASIL, 2009), sendo a contagem realizada aos cinco dias e os resultados expressos em porcentagem.

Para o comprimento de plântulas, utilizaramse cinco subamostras de 20 sementes, em substrato rolo de papel germitest, dispostas e alinhadas na parte superior do papel de germinação, umedecido com água destilada na quantidade equivalente a 2,5 vezes o seu peso seco. Os rolos de papel foram colocados em sacos plásticos e acondicionados em germinador a $25^{\circ} \mathrm{C}$ e a avaliação foi realizada aos cinco dias, sendo medido o comprimento total de plântulas e de suas partes separadamente (hipocótilo e raiz) em centímetros, calculando-se o comprimento médio das plântulas e de suas partes por parcela, conforme metodologia descrita por NAKAGAWA (1999).

O delineamento experimental utilizado foi inteiramente casualizado em esquema fatorial $4 \times 3 \times 5$ (período de armazenamento x polímero x tratamento) em três repetições. As médias foram submetidas à análise de variância, sendo os efeitos dos tratamentos avaliados pelo teste $\mathrm{F}$ e, quando significativa, submetidas à adequação de modelo polinomial. Também foram verificados efeitos latentes (após o período final de armazenamento, utilizando apenas as análises realizadas aos 180 dias de armazenamento), sendo utilizado o delineamento inteiramente casualizado em esquema fatorial $3 \times 5$ (polímeros $\mathrm{x}$ tratamentos), totalizando quinze tratamentos em três repetições, sendo os efeitos dos tratamentos avaliados pelo teste $\mathrm{F}$ e, quando significativas as médias, comparadas pelo teste de Tukey a 5\% de significância.

\section{RESULTADOS E DISCUSSÃO}

Armazenamento

Analisando a germinação das sementes durante o período de armazenamento, verificou-se que houve interação entre polímeros e época de avaliação, já que se observa que o armazenamento não trouxe prejuízos à germinação, com as médias se adequando ao modelo quadrático, com tendência a manter a germinação inicial até os 120 dias de armazenamento e reduzindo de 4, 6 e $7 \%$ somente após o período de 180 dias de armazenamento para os tratamentos sem polímero, com polímero líquido e polímero em pó, respectivamente (Figura 1A). Ainda é importante ressaltar que a germinação inicial das sementes recobertas com o polímero em pó foi 3 e $4 \%$ inferior à daquelas da testemunha e do polímero líquido, respectivamente. Resultados similares foram encontrados por PEREIRA et al. (2007), ao verificarem melhor desempenho na germinação durante o período de armazenamento de sementes de soja tratadas com fungicidas em relação àquelas não tratadas e, para sementes não tratadas, melhor desempenho com o uso de polímeros, demonstrando que os polímeros podem ser utilizados junto com outros produtos para proteger as sementes durante o armazenamento.

Novamente, os tratamentos mantiveram a germinação até os 120 dias de armazenamento na avaliação da primeira contagem de germinação, sendo que, para as sementes dos tratamentos sem polímero, com polímero líquido e com polímero em pó, após 180 dias de armazenamento, houve uma redução de 5, 8 e $5 \%$, respectivamente (Figura 1B). Porém, verifica-se que os valores na primeira contagem de germinação das sementes recobertas com o polímero foi, inicialmente, 7 e $8 \%$ inferiores àqueles do tratamento sem polímero e ao polímero líquido, respectivamente. Dessa forma, é possível notar um efeito prejudicial à germinação das sementes, causado pelo polímero em pó desde a avaliação inicial.

Em sementes de feijoeiro tratadas com fungicida e recobertas com polímeros vinílicos, ocorreram menores porcentagens no teste de primeira contagem de germinação em relação às sementes não recobertas com polímeros; essa menor porcentagem obtida no teste de primeira contagem de germinação não foi atribuída a uma redução no vigor das sementes e sim a uma redução na velocidade de germinação, ocasionada por uma barreira física proporcionada pelo polímero, que interferiu na velocidade de absorção de água pelas sementes, uma vez que não houve prejuízos à germinação, pois, em alguns tratamentos envolvendo polímeros, há melhor desempenho (PIRES et al., 2004). Neste trabalho, verificou-se uma redução tanto na germinação quanto no vigor (primeira contagem de germinação) proporcionada pelo polímero em pó, não se podendo atribuir essa redução na germinação simplesmente a uma barreira proporcionada pelo polímero à absorção de água, que acarretou em um atraso na germinação.

Os resultados obtidos podem indicar que os polímeros interagem diferentemente com o tegumento das sementes, o que pode resultar em perda de germinação. DUAN e BURRIS (1997), verificando o efeito do recobrimento de sementes com polímeros, em 12 lotes de nove cultivares de beterraba açucareira, verificaram redução significativa na germinação de seis deles após o recobrimento com polímero, havendo diferença entre cultivares e lotes de uma mesma cultivar. O recobrimento após a retirada do pericarpo, no cultivar que com maior sensibilidade não reduziu a germinação, 


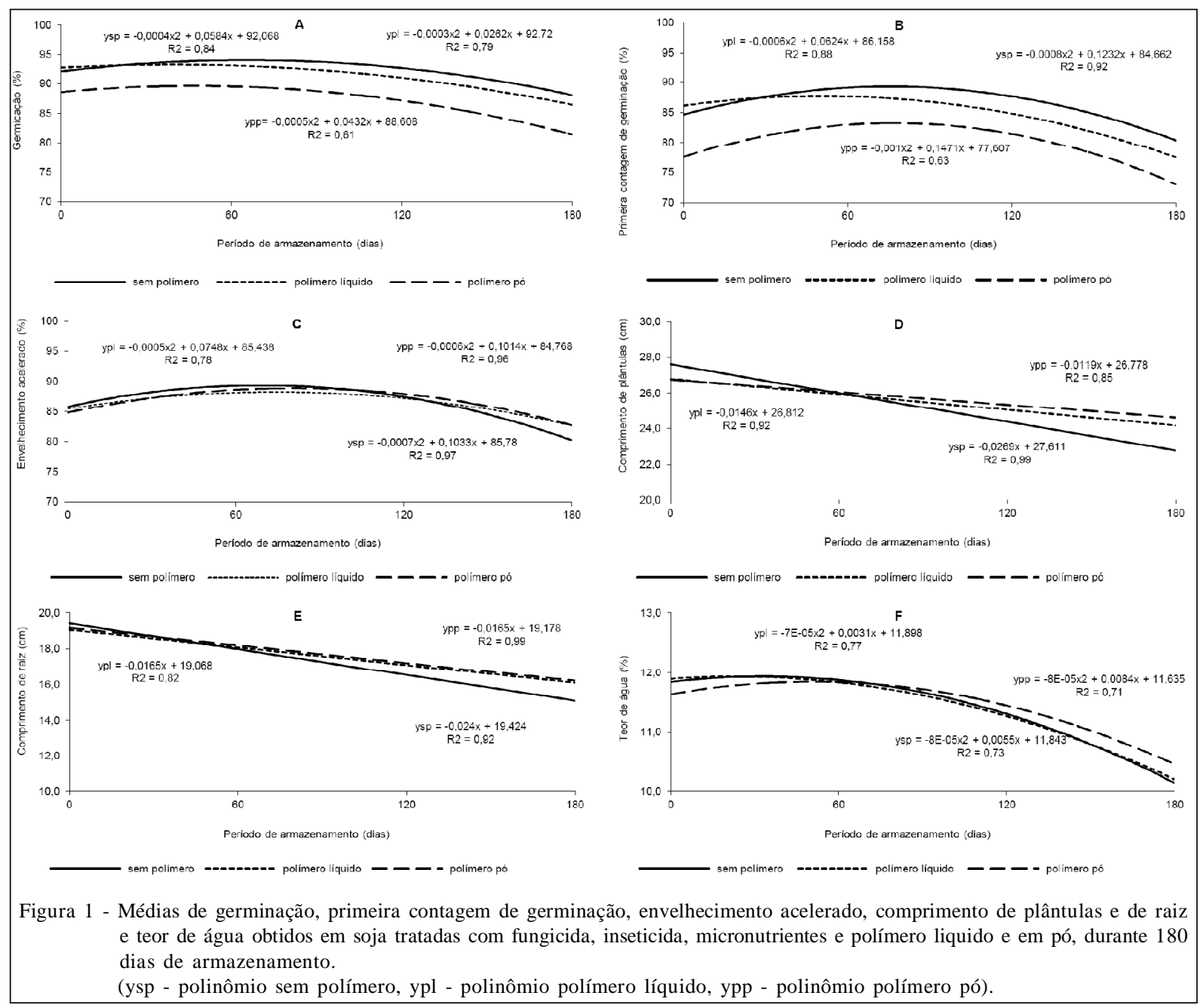

demonstrando uma associação negativa entre polímero e pericarpo que afetou o desempenho das sementes.

A diferença inicial observada na germinação e no vigor (primeira contagem de germinação) entre os demais tratamentos em relação ao polímero em pó não se repetiu no envelhecimento acelerado, no qual novamente as sementes dos tratamentos tenderam a manter a germinação até os 120 dias de armazenamento, período em que o desempenho das sementes foi similar (Figura 1C). Entretanto, a partir desse período de armazenamento, o desempenho das sementes com polímero foi levemente superior, com uma redução na germinação entre $2 \%$ após o envelhecimento e nas sementes sem polímero houve uma redução superior a $4 \%$.

Essa tendência de maior vigor após o período de armazenamento das sementes dos tratamentos com polímeros pode significar que o polímero em pó tenha favorecido alguns fungos que possam ter prejudicado a avaliação no teste de germinação, o que não ocorreu após o envelhecimento acelerado, pois segundo BAYS et al. (2007), tanto a temperatura como a umidade elevada em que as sementes ficam expostas durante o envelhecimento inibem a manifestação de determinados fungos, podendo a germinação obtida após o envelhecimento ser superior à germinação inicial.

O teste de comprimento de plântulas detectou melhor desempenho para os tratamentos com polímero durante o período de armazenamento (Figura 1D), para os quais constatou-se uma redução no comprimento de plântulas de apenas $0,4 \mathrm{~cm}$ ao mês, quando comparados com $0,8 \mathrm{~cm}$ dos tratamentos sem polímero. Nos tratamentos com polímero, também houve melhor desempenho no comprimento de raiz, com uma redução de $0,5 \mathrm{~cm}$ ao mês quando comparados com $0,7 \mathrm{~cm}$ dos tratamentos sem polímero (Figura 1E). O comprimento de hipocótilo não foi um teste sensível para avaliar o vigor durante o período de armazenamento.

Ciência Rural, v.41, n.10, out, 2011. 
Os resultados obtidos no comprimento de plântulas e de raiz, semelhante ao observado para o teste de envelhecimento acelerado e ao contrário das respostas observadas para os testes de germinação e primeira contagem de germinação, indicaram um melhor desempenho obtido com o uso de polímeros. Embora os diferentes testes tenham detectado pequenas diferenças na qualidade das sementes, do ponto de vista prático, pode-se afirmar que não houve prejuízos à qualidade das sementes durante o período de armazenamento, e que há viabilidade da incorporação desses produtos para proteger o desempenho delas.

A redução do teor de água após o período de 180 dias de armazenamento foi de 1,6\% para as sementes dos tratamentos sem polímero, $1,7 \%$ para aquelas do polímero líquido e 1,1\% para as sementes dos tratamentos com polímero em pó (Figura 1E), o que significa uma redução mensal de 0,$3 ; 0,3$ e $0,2 \%$, respectivamente. Embora seja uma diferença pequena, verifica-se uma tendência do polímero em pó manter a menor variação no teor de água.

No armazenamento de sementes de soja a frio, tratadas com fungicidas ou não, houve uma redução no teor de água de $0,6 \%$ ao mês, independente do tratamento (CARDOSO et al., 2004), demonstrando pequena troca de vapor de água entre as sementes e o ar do ambiente de armazenamento.

Efeitos latentes

Após seis meses de armazenamento, houve interação significativa entre as médias referentes à germinação de sementes tratadas com os polímeros, com melhor desempenho daquelas submetidas aos tratamentos sem polímero e com polímero líquido quando comparados àquelas tratadas com polímero em pó para os tratamentos testemunha, inseticida $\mathrm{e}$ micronutriente (Tabela 1). Para as sementes tratadas com fungicida, aquelas recobertas com o polímero em pó expressaram germinação inferior àquelas recobertas com o polímero líquido, enquanto que, para as sementes tratadas com micronutrientes, o desempenho das recobertas com o polímero em pó foi inferior ao tratamento testemunha (sem polímero). Nas sementes tratadas com inseticida, constatou-se menor germinação quando comparadas àquelas da testemunha e do micronutriente nos tratamentos sem polímero e a todos os outros tratamentos, excetuando o micronutriente no polímero líquido.

Na primeira contagem de germinação, após os seis meses de armazenamento (Tabela 1), as sementes dos tratamentos sem polímero expressaram melhor desempenho para a testemunha e o micronutriente. Na comparação entre os polímeros, o tratamento sem polímero foi melhor que aquele com polímero em pó para o tratamento fungicida + inseticida + micronutriente. Também se verificou melhor desempenho do polímero líquido que do polímero em pó para os tratamentos testemunha e fungicida + inseticida + micronutrientes.

No teste de envelhecimento acelerado, para a testemunha, o polímero líquido foi superior ao polímero em pó, porém não diferiu dos tratamentos sem polímero, enquanto para o fungicida não houve diferença estatística entre os polímeros. Para as sementes tratadas com inseticida, o desempenho daquelas recobertas com polímero foi superior as da testemunha sem polímero, enquanto que para as sementes tratadas com micronutriente, nas recobertas com polímero em pó, houve vantagem em relação àquelas do polímero líquido (Tabela 1).

Não houve interação significativa entre polímeros e tratamentos para o comprimento de plântulas e de raiz (Tabela 2), verificando-se apenas efeito principal de polímero com as médias do comprimento de plântulas, com melhores resultados

Tabela 1 - Germinação, primeira contagem de germinação e envelhecimento acelerado de sementes de soja da cultivar 'CD 209' tratadas com fungicida, inseticida, micronutrientes e recobertas com polímero líquido e em pó, após 180 dias de armazenamento.

\begin{tabular}{|c|c|c|c|c|c|c|c|c|c|}
\hline \multirow{2}{*}{ Tratamentos } & \multicolumn{3}{|c|}{-------------Germinação------------- } & \multicolumn{3}{|c|}{---------Primeira contagem--------- } & \multicolumn{3}{|c|}{-----Envelhecimento acelerado----- } \\
\hline & $\mathrm{S} / \mathrm{P}^{*}$ & PL & PP & $\mathrm{S} / \mathrm{P}$ & PL & PP & $\mathrm{S} / \mathrm{P}$ & PL & PP \\
\hline Testemunha & $92 \mathrm{Aa}^{* *}$ & $87 \mathrm{Aa}$ & $79 \mathrm{Ba}$ & $86 \mathrm{Aa}$ & $78 \mathrm{Ba}$ & $70 \mathrm{Cb}$ & $78 \mathrm{ABab}$ & $82 \mathrm{Aa}$ & $75 \mathrm{Bc}$ \\
\hline Fungicida & $86 \mathrm{ABab}$ & 89 Aa & $82 \mathrm{Ba}$ & $77 \mathrm{Ab}$ & $80 \mathrm{Aa}$ & $74 \mathrm{Aab}$ & $85 \mathrm{Aa}$ & $84 \mathrm{Aa}$ & $87 \mathrm{Aa}$ \\
\hline Inseticida & $83 \mathrm{Ab}$ & $79 \mathrm{Ab}$ & $81 \mathrm{Aa}$ & $73 \mathrm{Ab}$ & $69 \mathrm{Ab}$ & $69 \mathrm{Ab}$ & $76 \mathrm{Cb}$ & $83 \mathrm{Aa}$ & $85 \mathrm{Aab}$ \\
\hline Micronutriente & $90 \mathrm{Aa}$ & $86 \mathrm{ABab}$ & $81 \mathrm{Ba}$ & $87 \mathrm{Aa}$ & $79 \mathrm{Ba}$ & $77 \mathrm{Ba}$ & $81 \mathrm{ABab}$ & $80 \mathrm{Ba}$ & $89 \mathrm{Aa}$ \\
\hline $\mathrm{F}+\mathrm{I}+\mathrm{M}^{* * *}$ & $88 \mathrm{Aab}$ & $88 \mathrm{Aa}$ & $78 \mathrm{Ba}$ & $78 \mathrm{Ab}$ & $79 \mathrm{Aa}$ & $69 \mathrm{Bb}$ & $80 \mathrm{Aab}$ & $82 \mathrm{Aa}$ & $80 \mathrm{Ab}$ \\
\hline $\mathrm{CV}(\%)$ & 4,7 & 4,8 & 4,2 & 7,3 & 6,0 & 6,0 & 6,2 & 4,4 & 9,0 \\
\hline
\end{tabular}

*S/P - sem polímero, PL - polímero líquido, PP - polímero em pó.

*** Médias seguidas da mesma letra, maiúscula na linha e minúscula na coluna, não diferem entre si (Tukey $5 \%$ ).

${ }^{* * *}$ F + I + M - Fungicida + Inseticida + Micronutrientes. 
Tabela 2 - Comprimento de plântula, do hipocótilo e da raiz de plântulas oriundas de sementes de soja, cultivar 'CD 209' tratadas com fungicida, inseticida, micronutrientes e recobertas com polímero líquido e em pó, após 180 dias de armazenamento.

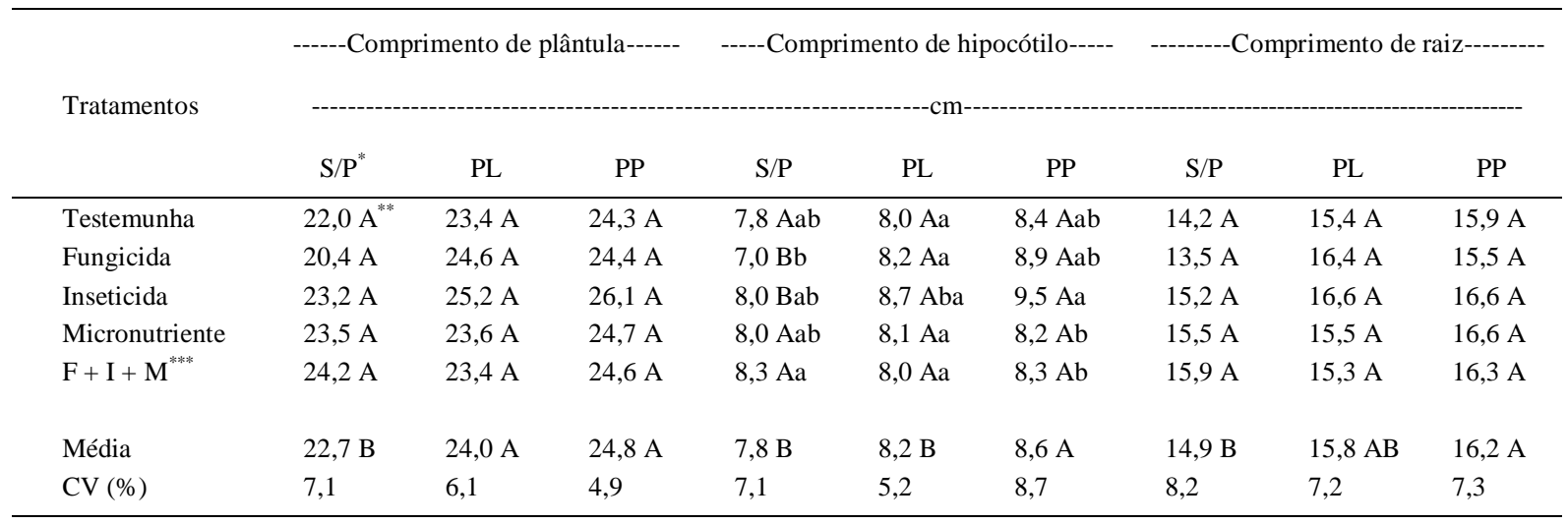

${ }^{*} \mathrm{~S} / \mathrm{P}$ - sem polímero, PL - polímero líquido, PP - polímero pó.

${ }_{* *}^{*}$ Médias seguidas da mesma letra, maiúscula na linha e minúscula na coluna, não diferem entre si (Tukey $5 \%$ ).

${ }^{* * *} \mathrm{~F}+\mathrm{I}+\mathrm{M}$ - Fungicida + Inseticida + Micronutrientes.

para os tratamentos com polímeros e o polímero em pó com maior comprimento de raiz que os tratamentos sem polímero. Para o comprimento de hipocótilo, as sementes tratadas com fungicida expressaram, para o recobrimento com polímero, médias superiores ao tratamento sem polímero, por outro lado, para o tratamento de sementes com inseticida, no recobrimento com polímero em pó, o valor foi superior ao tratamento sem polímero.

Esses resultados ratificam os dados da figura 1, em que se verificou uma tendência do polímero em pó em proporcionar menor germinação das sementes, demonstrando ainda que o efeito do polímero sobre o desempenho das sementes pode mudar, dependendo da interação entre o polímero e o produto utilizado, ou seja, embora os polímeros protejam o desempenho das sementes durante o armazenamento, a interação dos polímeros com alguns produtos pode causar efeito adverso após 180 dias de armazenamento.

\section{CONCLUSÃO}

O recobrimento de sementes de soja ' $\mathrm{CD}$ 209' com polímeros e produtos protetores as protege durante o armazenamento, enquanto o polímero em pó reduz a germinação das sementes e há interação entre polímeros e produtos sobre o desempenho de sementes após 180 dias de armazenamento.

\section{REFERÊNCIAS}

BAYS, R. et al. Recobrimento de sementes de soja com micronutrientes, fungicida e polímero. Revista Brasileira de Sementes, v.29, n.2, p.60-67, 2007. Disponivel em: <http:/
/www.scielo.br/scielo.php?script=sci_arttext\&pid=S0101$31222007000200009 \& \operatorname{lng}=\mathrm{es} \& \mathrm{nrm}=\mathrm{iso}>$. Acesso em: $20 \mathrm{fev}$. 2011. doi: 10.1590/S0101-31222007000200009.

BRASIL. Ministério da Agricultura, Pecuária e Abastecimento. Regras para análise de sementes. Brasília: Secretaria Nacional de Defesa Agropecuária, Departamento Nacional de Defesa Vegetal, 2009. 398p.

CARDOSO, P.C. et al. Armazenamento em sistema a frio de sementes de soja tratadas com fungicida. Revista Brasileira de Sementes, v.26, n.1, p.15-23, 2004. Disponível em: <http:/ /www.scielo.br/scielo.php?script=sci_arttext\&pid=S0101$31222004000100003 \& \operatorname{lng}=$ pt\&nrm=iso $>$. Acesso em: 20 fev. 2011. doi: 10.1590/S0101-31222004000100003.

DUAN, X.; BURRIS, J.S. Film coating impairs leaching of germination inhibitors in sugar beet seed. Crop Science, v.37, n.2, p.515-520, 1997. Disponível em: <http://crop.scijournals.org/ cgi/content/abstract/37/2/515>. Acesso em: 20 fev. 2011. doi:10.2135/cropsci1997.0011183X003700020034x.

GRUTZMACHER, A.D. Tratamento de sementes de soja também com inseticida. Seed News, v.11, n.3, p.8-10, 2007.

HENNING, A.A. Patologia e tratamento de sementes: noções gerais. 2.ed. Londrina: EMBRAPA-CNPSo, 2005. 52p. (EMBRAPA-CNPSo, Documentos 264).

KIRKBY, E.A.; RÖMHELD, V. Micronutrientes na fisiologia de plantas: funções, absorção e mobilidade. Norcross: International Plant Nutrition Institute 007, 2007. 24p. (Encarte técnico, informações agronômicas n.18).

KUNKUR, V. et al. Effect of seed coating with polymer, fungicide and insecticide on seed quality in cotton during storage. Karnataka Journal of Agricultural Sciences, v.20, n.1, p.137-139, 2007. Disponível em: <http://203.129.218.157/ ojs/index.php/kjas/article/view/42/42>. Acesso em: 20 fev. 2011.

MARCOS FILHO, J. Fisiologia de sementes de plantas cultivadas. Piracicaba: FEALQ, 2005. 495p.

NAKAGAWA, J. Testes de vigor baseados no desempenho das plântulas. In: KRZYZANOWSKI, F.C. et al. Vigor de 
sementes: conceitos e testes. Londrina: ABRATES, 1999. p.2.1-2.24.

PEREIRA, C.E. et al. Qualidade fisiológica de sementes de milho tratadas associadas a polímeros durante o armazenamento. Ciência e Agrotecnologia, v.29, n.6, p.1201-1208, 2005. Disponível em: $<$ http://www.scielo.br/scielo.php?script=sci_arttext $\&$ pid $=$ S 1413 $70542005000600014 \& \operatorname{lng}=\mathrm{en} \& \mathrm{nrm}=\mathrm{iso}>$. Acesso em: $20 \mathrm{fev}$. 2011. doi: 10.1590/S1413-70542005000600014.

PEREIRA, C.E. et al. Desempenho de sementes de soja tratadas com fungicidas e peliculizadas durante o armazenamento. Ciência e Agrotecnologia, v.31, n.3, p.656-665, 2007. Disponível em: $<$ http://www.scielo.br/scielo.php?script=sci_arttext\&pid=S1413$70542007000300009 \& \operatorname{lng}=$ en $\& n r m=i s o>$. Acesso em: $20 \mathrm{fev}$. 2011. doi: 10.1590/S1413-70542007000300009.

PIRES, L.L. et al. Armazenamento de sementes de feijão revestidas com polímeros e tratadas com fungicidas. Pesquisa agropecuária brasileira, v.39, n.7, p.709-715, 2004. Available from: <http:// www.scielo.br/scielo.php?script $=$ sci_arttext\&pid $=$ S0 100 204X2004000700013\&lng=en\&nrm=iso>. Acesso em: $10 \mathrm{fev}$. 2011. ISSN 0100-204X. doi: 10.1590/S0100204X2004000700013. 